\title{
O JEITINHO BRASILEIRO: AS PEQUENAS CORRUPÇÕES DIÁRIAS E SEUS REFLEXOS NA MOROSIDADE DA JUSTIÇA
}

\author{
Sergio Pereira Braga ${ }^{1}$ \\ Eudes Vitor Bezerra ${ }^{2}$
}

RESUMO: O presente ensaio baseou-se na premissa de que o denominado "jeitinho brasileiro" pode contribuir para o aumento da morosidade da justiça, que é um dos grandes gargalos do Poder Judiciário na contemporaneidade. Destarte, o tema central deste artigo será demonstrar como as pequenas corrupções diárias e a não observância das leis e das regras de conduta podem impactar, negativamente, o andamento do nosso sistema judicial. Assim sendo, será utilizado o método hipotético-dedutivo, com a análise histórica e comparativa correlacionadas ao tema em comento.

Palavras-chave: Morosidade. Poder Judiciário. Jeitinho brasileiro.

\section{THE BRAZILIAN WAY: THE SMALL DAILY CORRUPTIONS AND ITS REFLECTIONS IN THE MOROSITY OF JUSTICE}

\begin{abstract}
The present essay was based on the premise that the so-called "Brazilian way" can contribute to an increase in the slowness of justice, which is one of the major bottlenecks of the Judiciary in contemporary times. Thus, the central theme of this article will be to demonstrate how small daily corruption and non-observance of laws and rules of conduct can negatively impact the progress of our judicial system. Therefore, the hypothetical-deductive method will be used, with historical and comparative analysis correlated to the theme in the commentary.
\end{abstract}

Keywords: Slowness. Judicial power. Brazilian way.

\section{INTRODUÇÃO}

A procura por atalhos, o improviso e a flexibilidade são características do brasileiro e espelham o modo de agir, sentir e falar. Em 2 de outubro de 2009, a cidade do Rio de Janeiro

\footnotetext{
${ }^{1}$ Doutorado em Direito pela Pontifícia Universidade Católica de São Paulo - PUC-SP, mestrado em Administração de Empresas pelo Centro Universitário FECAP , mestrado em Direito pela Universidade Nove de Julho, graduado em Direito pela Universidade São Judas Tadeu. Atualmente é diretor do curso de direito da Universidade Nove de Julho. Tem experiência na área de Direito, com ênfase em Direito Público, atuando principalmente nos seguintes temas: direito; gestão da justiça; reforma do judiciário; eficiência; educação e cidadania.

${ }^{2}$ Pós-Doutorando em Direito - UFSC. Doutor em Direito PUC/SP (2016). Mestre em Direito PUC/SP (2012). Pós-graduado em Docência Universitária UNINOVE (2013). Pós-graduado em Direito Civil e Direito Processual Civil UNISAL (2008). Graduado em Direito UNINOVE (2007). Coordenador do Curso de Direito da Universidade Nove de Julho. Membro do Núcleo Docente Estruturante do Curso de Direito da Universidade Nove de Julho. Professor de Ensino Superior e Pós-graduação na Universidade Nove de Julho - UNINOVE, Palestrante e Advogado militante em São Paulo. Associado do Conselho Nacional de Pesquisa e Pós-graduação em Direito - CONPEDI. Autor de Livro e Artigos Científicos.
} 
foi escolhida para ser a sede das Olímpiadas de 2016. A partir da escolha, o Rio de Janeiro teve 7 (sete) anos para edificar as instalações olímpicas e promover intervenções urbanísticas que seriam o verdadeiro legado das Olimpíadas para a cidade.

Além do aumento considerável ${ }^{13}$ nos custos inicialmente previstos para as obras, grande parte delas foram finalizadas poucos dias antes do início do evento, outras canceladas, como a limpeza da Baía da Guanabara, e algumas entregues com diversos problemas, como foi o caso da Vila Olímpica.

Os problemas nas instalações olímpicas fizeram com que numerosas delegações fossem proibidas, por seus dirigentes, como foi o caso da Austrália, de entrar nos apartamentos destinados à comissão técnica e aos atletas, já que apresentavam vazamentos, fiações soltas, falta de equipamentos, entre outros problemas.

Prontamente, o Prefeito do Rio de Janeiro à época, Eduardo Paes, e os responsáveis pelo comitê organizador local justificaram o atraso e afirmaram que "dariam um "jeitinho" e que tudo ficaria bem.

Ainda na semana que antecedeu a abertura dos Jogos Olímpicos, do Rio de Janeiro, o Presidente do Comitê Olímpico Internacional - COI, Thomas Bach, afirmou que os jogos seriam "a la Brasil"" numa clara referência à improvisação que é comumente associada ao país.

Há tempos, uma célebre frase atribuída ao General francês Charlles de Gaulle ": “- Le Brésil n'est pas un pays sérieux-" que em português significa "O Brasil não é um país sério" é um pronto retrato da visão que se tem sobre o Brasil e consequentemente sobre os brasileiros.

Um outro adjetivo comumente associado ao brasileiro e que se imbrica com o jeitinho é a mania de querer levar vantagem em tudo, a conhecida Lei de Gérson ${ }^{6}$.

\footnotetext{
${ }^{3}$ Diferentemente do que aconteceu na Copa do Mundo, a maior parte dos investimentos na Olimpíada tem origem privada por meios de patrocínios ou Parcerias Público-Privadas (PPPs). Enquanto no Mundial de Futebol a participação privada ficou em torno de $17,2 \%$, no Rio 2016, ela foi estimada em 58\%. PORTAL JOGOS LIMPOS. Olimpíadas. Disponível em: <http://www.jogoslimpos.org.br/destaques/olimpiada-rio-2016devecustar-r-367-bilhoes/>. Acesso em: 06 ago. 2016.

4 ESTADO DE SÃO PAULO. Caderno Olimpíadas. Edição de 1 ago. 2016. Disponível em: <http://digital.estada o.com.br/home.asp>. Acesso em: 06 ago. 2016. p. H2.

${ }^{5}$ Como esclareceu o então embaixador brasileiro em Paris, Carlos Alves de Souza, em seu livro Um embaixador em tempos de crise. Rio de Janeiro: Livraria Francisco Alves, 1979, p. 316, a frase atribuída a De Gaulle foi por ele, Carlos, proferida e não pelo General.

${ }^{6}$ No Brasil, uma das leis mais conhecidas é a Lei de Gérson. Segundo ela, se algo pode dar errado, não tem problema, pois mesmo que der errado, a gente dá um jeitinho de fazer parecer certo. Gérson de Oliveira foi quem
} 
As qualificações acima apontadas compõem um modo de agir ou um fenômeno sociológico conhecido como “jeitinho brasileiro". Trata-se de algo tão nosso quanto o carnaval e único como a jabuticaba ${ }^{7}$.

Assim, por meio do método hipotético-dedutivo e com aporte na pesquisa dogmática, no presente trabalho procurar-se-á demonstrar como a celeridade da justiça pode ser afetada pela cultura do "jeitinho brasileiro".

Com efeito, no primeiro capítulo trataremos da aversão do brasileiro no que tange ao cumprimento de regras, bem como a relativização ou flexibilidade ética que nos são tão comum nas relações sociais/interpessoais, tornando, assim, nosso país um caso único no mundo.

Já no segundo capítulo apresentaremos algumas definições e conceitos para o que se convencionou chamar de "jeitinho brasileiro", que em linhas gerais possui características positivas e negativas.

As pequenas corrupções diárias serão abordadas no terceiro capítulo, demonstrando-se que na maioria das vezes são realizadas sob o argumento da insignificância, ou como meio de se livrar do "excesso de burocracia", que dão sustentação às grandes corrupções experimentadas no Brasil na contemporaneidade.

Por derradeiro, no quarto capítulo, serão demonstrados os reflexos do jeitinho brasileiro na morosidade experimentada pelo nosso sistema de justiça.

\footnotetext{
ficou com a fama pela frase que batizou o jeitinho brasileiro, mas o fato é que a maioria do povo já se beneficiou com tal lei e ainda se gaba por ser mundialmente famosos por isso. A Lei de Gérson tem origem em uma propaganda que Gérson, um dos melhores meio-campistas da história do futebol brasileiro e ex-jogador de grandes times como o São Paulo Futebol Clube, fez para os cigarros Vila Rica no ano de 1976. Na peça publicitária, o boleiro fala sobre as vantagens do cigarro e pronuncia a seguinte frase: "É gostoso, suave e não irrita a garganta". Na sequência diz: "Por que pagar mais caro se o Vila me dá tudo aquilo que eu quero de um bom cigarro?". Depois de propagandear o cigarro e falar sobre o quanto o produto era bom, Gérson dá um sorrisinho malandro e solta a última e infeliz frase da propaganda: "Gosto de levar vantagem em tudo, certo?". Dessa forma, sintetizou de uma vez só o jeitinho brasileiro de fazer o errado parecer certo. SOUZA, Carlos Alves de. Um embaixador em tempos de crise. Rio de Janeiro: Francisco Alves, 1979. p. 316.

${ }^{7}$ Teoria da jabuticaba é tudo aquilo que só existe no Brasil, como essa saborosa fruta selvagem da respeitada família das mirtáceas (myrciaria jaboticaba). Isso significa, para ser rápido, pertencer a uma família de "explicações sociais" única e exclusiva neste planeta Terra, situação inédita no plano universal, que consiste em propor, defender e sustentar, contra qualquer outra evidência lógica em sentido contrário, soluções, propostas, medidas práticas, iniciativas teóricas ou mesmo teses (em alguns casos, até antíteses) que só existem no Brasil e que só aqui funcionam, como se o mundo tivesse mesmo de se curvar ante nossas soluções inovadoras para velhos problemas humanos e antigos dilemas sociais.
} 
Nesta toada, o presente ensaio apresenta um olhar diferenciado sobre condutas que, também, podem influenciar a lentidão da justiça.

\section{A aversão ao cumprimento de regras}

Antes de tratarmos do fenômeno, é preciso ponderar sobre algo que está intrinsicamente vinculado às condutas humanas, cuja relativização, flexibilidade ou mesmo seu esquecimento, fundamentam esse produto nacional chamado "jeitinho brasileiro". Estamos nos referindo a um conceito muito antigo, muito falado, mas pouco praticado: a Ética.

Trivializou-se o apelo à Ética, para servir a objetivos os mais diversos, nem todos eles compatíveis com o seu significado. "Perdeu-se, no trajeto, fidelidade ao núcleo conceitual que a palavra pretende transmitir. Além disso, a utilização excessiva de certas expressões compromete o seu sentido, como se o emprego frequente implicasse debilidade semântica" ${ }^{\text {. }}$.

Ética é a ciência do comportamento moral dos homens em sociedade. Ou seja, é a ciência de uma forma específica de sociedade ${ }^{9}$. Assim como os problemas teóricos morais não se identificam com os problemas práticos, embora estejam estritamente relacionadas, uma vez que ambas significam etimologicamente costume, não se confundem ética e moral.

A ética se relaciona com diversas áreas do conhecimento, entre elas a filosofia, o direito, a antropologia e a sociologia. O estudo da ética, sob a ótica da sociologia e da antropologia, visa ao comportamento do homem como ser social e do ponto de vista de determinadas relações.

Para Aristóteles ${ }^{10}$, a moralidade busca o alcance de um fim. A felicidade é a finalidade última da eticidade clássica. Para os medievais, os deveres são advindos de uma fonte externa ao sujeito, vindos de Deus, e a moralidade, em muitas ocasiões, se dá por meio de uma condicionante finalística: o agir de acordo com o dever é a forma da salvação.

\footnotetext{
${ }^{8}$ NALINI, José Renato. Ética geral e profissional. 10.ed. São Paulo: Revista dos Tribunais, 2013. p. 24.

${ }^{9}$ VÁZQUEZ, Adolfo Sanchez. Ética. 28.ed. Rio de Janeiro: Civilização Brasileira: 2006. p. 23.

${ }^{10}$ ARISTÓTELES. A política. Rio de Janeiro: Ed. De Ouro, v. I., 1965. p. 9.
} 
O homem, por ser um ser social ${ }^{11}$, é sujeito e objeto do comportamento moral de uma dada sociedade. Ele se desenvolve sob o manto de uma determinada moral.

Segundo Adolfo Sanchez Vázquez ${ }^{12}$ :

O sujeito do comportamento moral é o indivíduo concreto, mas, sendo um ser social $\mathrm{e}$, independentemente do grau de consciência que tenha disto, parte de determinada estrutura social e inserido numa rede de relações sociais, o seu modo de comportarse moralmente não pode ter um caráter puramente individual, e sim social. Os indivíduos nascem de uma determinada sociedade na qual vigoram uma moral efetiva que não é a invenção de cada um em particular, mas que cada um encontra como dado objetivo, social.

Em Immanuel Kant ${ }^{13}$, a moral designa o conjunto de princípios gerais e a ética, sua aplicação concreta. Para o filósofo, o fundamento último que leva à moralidade é apenas uma boa vontade: "Neste mundo, e até também fora dele, nada é possível pensar que possa ser considerado como bom sem limitação a não ser uma só coisa: uma boa vontade”.

A boa vontade é elevada como eixo instituidor da moralidade kantiana. Trata- se de um querer somente pelo querer. Essa é uma visão da moralidade muito distinta daquela construída pelos antigos ou pelos medievais.

A universalidade é a marca dos imperativos categóricos. Isso quer dizer, há uma pressuposição da aplicação universal e de um querer advindo de uma pressuposta universalidade dos agentes. A universalidade é uma medida fundamental do pensamento pratico kantiano e sua flexibilização, abominável à razão.

Exemplo clássico dessa visão de mundo kantiana está na possibilidade moral da mentira. Se o imperativo categórico fosse flexível, não necessariamente universal, mentir seria legítimo moralmente. Mas, para Immanuel Kant, com isso não seria possível pressupor a vida em sociedade, nem seriam possíveis os contratos, se fosse legítimo moralmente aos contratantes mentirem quando do acordo de vontades. Somente a verdade pode ser universalizada enquanto lei moral, e, assim, somente ela é expressão de uma racionalidade que se compreende em todos os homens. Não mentir seria, pois, o desdobramento necessário do imperativo categórico.

Nesse sentido, a flexibilização do dever moral que nos obriga a cumprir o que foi acordado, de respeitar as leis, sejam elas escritas ou não, de não querer levar vantagem, de

\footnotetext{
${ }^{11}$ ARISTÓTELES, op. cit. p.10

${ }^{12}$ VÁZQUEZ, Adolfo Sanchez. Ética. 28.ed. Rio de Janeiro: Civilização Brasileira: 2006. p. 31.

${ }^{13}$ KANT, Immanuel. Crítica da razão pura. 3.ed. São Paulo: Nova cultural, 1987. p.35.
} 
não realizar pequenas corrupções, de não mentir para obter nossos resultados ou nos proteger da descoberta da verdade, nos mostra que, há muito tempo - desde a nossa colonização -, a sociedade brasileira se afastou do imperativo categórico kantiano.

\section{Jeitinho Brasileiro}

Cumpre-nos, então, identificar o que vem a ser o chamado "jeitinho brasileiro". Antes de conceituá-lo, é preciso definir quem é o brasileiro. O que o torna diferente de um americano ou de um francês? Qual a singularidade do brasileiro? Qual o traço diferencial que lhe permite imprimir em suas ações um estilo característico e único no mundo?

Para responder a essas indagações, nada melhor do que nos valermos dos ensinamentos de Roberto Da Matta ${ }^{14}$, que, em poucas linhas, aponta o que é ser brasileiro:

Sei, então, que sou brasileiro e não norte-americano, porque gosto de comer feijoada e não hambúrguer; porque sou menos receptivo a coisas de outros países, sobretudo costume e ideias; porque tenho um agudo sentido de ridículo para roupas, gestos e relações sociais; porque vivo no Rio de Janeiro e não em Nova York; porque falo português e não inglês; porque, ouvindo música popular, sei distinguir imediatamente um frevo de um samba; porque futebol para mim é um jogo que se pratica com os pés e não com as mãos; porque vou à praia para ver e conversar com os amigos, ver as mulheres e tomar sol, jamais para praticar um esporte; porque sei que no carnaval trago à tona minhas fantasias sociais e sexuais; porque sei que não existe jamais um "não" diante de situações formais e que todos admitem um "jeitinho" pela relação pessoal e pela amizade; porque entendo que ficar malandramente "em cima do muro" é algo honesto, necessário e prático no caso do meu sistema; porque acredito em santos católicos e também nos orixás africanos; porque sei que existe destino e, no entanto, tenho fé no estudo, na instrução e no futuro do Brasil; porque sou leal a meus amigos e nada posso negar a minha família; porque, finalmente, sei que tenho relações pessoais que não me deixam caminhar sozinho neste mundo, como fazem meus amigos americanos, que sempre se veem e existem como indivíduos.

A simpatia e a cordialidade do brasileiro são ingredientes essências para a cultura do jeitinho. A aparência pessoal também pode ser um fator determinante para o sucesso da forma não tradicional de se resolver assuntos. Embora todas as pessoas reconheçam que esses fatores influem, nunca chegam a ser apontados como elementos decisivos. São importantes sim, mas até certo ponto, e podem ser utilizados contra as pessoas, caso elas manipulem essas categorias de forma autoritária.

${ }^{14}$ DA MATTA, Roberto. O que faz o brasil, Brasil?. Rio de Janeiro: Rocco, 1986. p.16-17 
A aversão ao cumprimento de regras e de prazos não é uma atitude exclusivamente brasileira. No entanto, essa capacidade de agir fora das normas e do padrão é algo acentuado e propagado no Brasil a partir de uma expressão romântica e singela denominada "jeitinho" brasileiro.

\title{
Para Lívia Barbosa ${ }^{15}$
}

\begin{abstract}
O jeitinho é sempre de uma forma especial de se resolver algum problema ou situação difícil ou proibida, ou uma solução criativa para alguma emergência seja sob a forma de burla de alguma regra ou norma preestabelecida, seja sob forma de conciliação, esperteza ou habilidade. Para que uma determinada situação seja considerada "jeitinho", necessita-se de acontecimentos imprevistos e adversos ao objetivo do indivíduo. Para resolvê-la é necessária uma maneira especial, isto é, eficiente e rápida de tratar o problema. Não serve qualquer estratégia. A que for adotada tem de produzir resultados no curtíssimo prazo. E mais, a não ser estas qualificações nenhuma outra se faz necessária para caracterizar o "jeitinho". Não importa que a solução seja definitiva ou não, ideal ou provisória, legal ou ilegal.
\end{abstract}

João Camilo de Oliveira Torres ${ }^{16}$ afirma que o "jeitinho" é um estilo peculiarmente brasileiro, produzido pela universalidade de tradições culturais, pelo desafio inicial da realidade brasileira que conduziu os primeiros habitantes a criar novas formas de vida, pelo caráter mestiço de nossa formação social, e pela formação humanística dada pelos jesuítas, de base generalista e, portanto, com pouca capacitação para a resolução de problemas definidos.

Roberto da $\mathrm{Matta}^{17}$ indica que o "jeitinho" é um modo e um estilo de realizar. É sobretudo, um modo simpático, desesperado ou humano de relacionar o impessoal com o pessoal; nos casos - ou no caso - de permitir juntar um problema pessoal (atraso, falta de dinheiro, ignorância das leis por falta de divulgação, confusão no texto ou ambiguidade, má vontade do aplicador ou do uso beneficiário, lei injusta, feita sob encomenda para situações específicas e aplicada para todos) com um problema impessoal.

O "jeitinho" é uma ação conhecida e largamente difundida na cultura brasileira. Seu uso não possui distinção de cor, raça, credo ou posição social. Não é só um mecanismo de ajuste à realidade institucional brasileira, mas também um elemento de identidade positiva e negativa.

\footnotetext{
${ }^{15}$ BARBOSA, Lívia. O jeitinho brasileiro: a arte de ser mais igual do que os outros. Rio de Janeiro: Elsevier, 2006. p. 41.

${ }^{16}$ OLIVEIRA TORRES, João Camilo de. Interpretação da realidade brasileira. Rio de Janeiro: José Olympio, 1973. p. 213-214.

${ }^{17}$ DA MATTA, Roberto. O que faz o brasil, Brasil?. Rio de Janeiro: Rocco, 1986. p. 100.
} 


\subsection{Jeitinho Brasileiro - Identidades Positivas e Negativas}

Como fatores positivos, associados ao "jeitinho brasileiro", temos a cordialidade, a flexibilidade, a resiliência, a alegria, a simpatia, o querer estar junto, a receptividade, a ausência de barreiras, os beijos e os abraços que são trocados mesmo com pessoas desconhecidas, a inventividade e o jogo de cintura.

Ressaltando a inventividade do brasileiro, Stelio Lourenço Rega ${ }^{18}$ afirma que:

Uma das facetas positivas mais amplas do "jeitinho" é a sua inventividade e criatividade. O "jeitinho" está impregnado duma energia vital que, em algumas ocasiões ameniza uma situação difícil livrando a pessoa do aperto e proporcionando a sua libertação. A criança que nasceu aleijada sem poder andar e aprende a se arrastar sobre uma madeira com rolamentos velhos de carro. Reage as limitações da vida dando um "jeitinho" com inventividade e criatividade.

A capacidade de adaptação às situações inesperadas é outra marca do brasileiro. Essa habilidade para dar um "jeitinho" tem criado no brasileiro uma rápida inteligência, permitindo-lhe escapar de situações de extrema dificuldade. A adaptabilidade e a flexibilidade são encorajadas porque a qualquer momento pode-se ter a necessidade ou oportunidade para dar um "jeitinho" 19 .

Betânia Barros e Marco Prates ${ }^{20}$ apresentam a flexibilidade como uma categoria de duas faces, denominadas adaptabilidade e criatividade:

A flexibilidade representa, na verdade, uma categoria com duas faces que denominamos de adaptabilidade e de criatividade, ambas reconhecidamente apontadas até pelos estrangeiros que nos visitam. (...) O conceito de adaptabilidade, visto pelo lado processual, não é uma criação em sentido puro como a produção de algo novo. É uma capacidade criativa que se exercita dentro de determinados limites prefixados. Este contorno restritivo é exatamente o processo que decorre no lado do subsistema institucional, no qual existe um reconhecimento das normas e em função delas resulta um ajustamento de elementos operativos, criando apenas novos hábitos condizentes com nossa maneira de ser.

O “jeitinho" também é conciliador, fazendo com que situações que pareciam ser desfavoráveis possam ser alteradas com base, muitas vezes, em argumentos apenas de cunho

${ }^{18}$ REGA, Lourenço Stelio. Dando um jeito no jeitinho: como ser ético sem deixar de ser brasileiro. São Paulo:

Mundo Cristão, 2000. p. 67.

19 BURNS, Barbara Helen. Teaching cross-cultural missions based on biblical theology. Implications of ephesians for the brazilian church. Deerfield, Illinois: Trinity. Tese (não publicada), 1987. p. 66.

${ }^{20}$ BARROS, Betania Tannure de; PRATES, Marco Aurélio. O estilo brasileiro de administrar. São Paulo: Editora Atlas, 1996. p. 68-69 
emocional ou sentimental, ainda que isso signifique a desobediência à norma de conduta, moral ou legal.

Do ponto de vista negativo, são atributos do brasileiro a esperteza, o descumprimento consciente ou aplicação seletiva das leis, o uso pessoal dos contatos sociais, o desprezo às formalidades, a falta de planejamento, o não cumprimento de prazos.

Todas essas atitudes são percebidas e reconhecidas pelos brasileiros como elementos que nos definem como país e como povo. Portanto, longe de ser algo escuso, embaraçoso, o jeitinho é reconhecido, admitido, louvado e condenado ${ }^{21}$. É um mecanismo característico da sociedade brasileira e envolve a quebra de regras, leis, padrões ou condutas obrigatórias.

A cultura brasileira é a do "jeitinho". Em outras palavras, como foco cultural, o "jeitinho" é um instrumento que cria ou inibe atitudes e comportamento. Assim, o "jeitinho" cria hábitos, influencia nossas decisões e acaba se tornando como que uma lei interior dentro de nós e que quer governar nossas escolhas ${ }^{22}$.

\section{As pequenas corrupções diárias}

O "jeitinho" brasileiro também pode ser interpretado por uma outra perspectiva, ou seja, como uma forma de superar o excesso de leis e a burocracia. Como enfatiza Faoro ${ }^{23}$, há em nossa sociedade um exagerado apego às leis, fato que propiciou o aparecimento do formalismo. Segundo ele, as leis são elaboradas com frases elegantemente construídas, mas que pecam por apresentar um conteúdo muito diferente dos costumes e até mesmo das necessidades daqueles a quem se destinam.

Para Fred Warren Riggs ${ }^{24}$, o formalismo é a diferença entre a conduta concreta e a norma que estabelece como essa conduta deveria ser, sem que tal diferença implique punição

\footnotetext{
${ }^{21}$ BARBOSA, Lívia. O jeitinho brasileiro: a arte de ser mais igual do que os outros. Rio de Janeiro: Elsevier, 2006. p. 32.

${ }^{22}$ REGA, Lourenço Stelio. Dando um jeito no jeitinho: como ser ético sem deixar de ser brasileiro. São Paulo: Mundo Cristão, 2000. p. 58

${ }^{23}$ FAORO, Raymundo. Os donos do poder. Porto Alegre: Globo, 2000. p.744-745

${ }^{24}$ RIGGS, Fred Warren. A ecologia da administração pública. Rio de Janeiro: FGV, 1966.p.65
} 
para o infrator da norma, ou seja, é aquilo que a lei diz e aquilo que acontece de fato, sem que isso gere punição para aquele que a descumpriu.

$\mathrm{Na}$ sociedade brasileira, a afirmação de que "todos são iguais perante a lei, mas a lei não é igual diante de todos" é algo corriqueiro, e se traduz numa conhecida frase corrente no país, expoente do pensamento político das oligarquias ainda dominantes: aos amigos, tudo; aos indiferentes nada; aos inimigos a lei.

Essa diferenciação não é nova. Raymundo Faoro ${ }^{25}$, tratando da corrupção à época do coronelismo ${ }^{26}$ aponta que:

Diante do guichê da coletoria o contribuinte solitário pagará todo o produto de seu trabalho, se a lei não for abrandada pelas circunstâncias. Um "simples" crime de morte, tratado pela lei, com o delegado, o promotor, os jurados, e o juiz não advertidos, dará cadeia. Outro será o resultado se o réu ou contribuinte tiverem um compadre ou um padrinho - "quem tem padrinho não morre pagão"; - agora, o bom atendimento torna-se questão de prestígio, que, desprezado, trará represálias, as duras represálias do sertão ou do campo.

É recorrente ouvirmos no Brasil que determinada "lei não pegou”. Nos países desenvolvidos, como por exemplo os Estados Unidos, a França ou a Inglaterra, não há prazer algum em se escrever normas que contrariam e, em alguns casos, aviltam o bom senso e as regras da própria sociedade, abrindo caminho para a corrupção burocrática e ampliando a desconfiança no poder público ${ }^{27}$.

Ainda de acordo com Fred Warren Riggs ${ }^{28}$, o formalismo faz com que os governos, as instituições e os entes de uma determinada sociedade possam, por meio de leis dar, negar, vetar e consentir direitos e deveres, sendo que o desrespeito a alguma norma faz com que haja uma generalização da desconfiança em torno da validade de todas as demais leis daquela sociedade.

É o caso, por exemplo, das malfadadas leis que obrigaram os motoristas a portarem em seus veículos kits de primeiros socorros e de extintores, sob pena de multa, sendo que ambas as leis, após causarem uma corrida desenfreada de motoristas às lojas que vendiam tais produtos, foram suspensas, pois não havia comprovação científica alguma de que o uso de

25 RIGGS, Fred Warren. A ecologia da administração pública. Rio de Janeiro: FGV, 1966.p.65.

${ }^{26} \mathrm{O}$ coronel, recebe seu nome da Guarda Nacional, cujo chefe, do regimento municipal, investia-se daquele posto, devendo a nomeação recair sobre pessoa socialmente qualificada, em regra detentora de riqueza, à medida que se acentua o teor de classe de sociedade. FAORO, Raymundo. Os donos do poder. Porto Alegre: Globo, 2000. p. 699.

${ }^{27}$ DA MATTA, Roberto. O que faz o brasil, Brasil?. Rio de Janeiro: Rocco, 1986. p. 97.

${ }^{28}$ RIGGS, op.cit., p.65. 
kits de primeiros socorros e extintores de incêndio, por pessoas não habilitadas, teria o condão de evitar maiores danos aos acidentados. Ao contrário disso, ficou comprovado que tal atitude poderia ser muito mais prejudicial.

É muito comum, quando viajamos para fora do país, em especial em cidades americanas, ficarmos fascinados e surpresos ao nos depararmos com veículos reduzindo a velocidade quando se aproximam de placas de trânsito que ordenam a parada, ainda que não haja nenhum pedestre atravessando a rua ou veículo na pista transversal e, principalmente, a existência de agente fiscalizador físico ou virtual por meio de câmeras e radares.

Ainda em cidades americanas, causa-nos estranheza ao paramos num cruzamento, sem qualquer fiscalização, e para cruzar a rua, o motorista do veículo que chegou depois, ainda que o fluxo lhe seja favorável, aguarda pacientemente a travessia do veículo que chegou primeiro, mesmo estando eles em lados opostos.

O fato é que, como aponta Roberto da Matta ${ }^{29}$ :

Vivemos em um sistema social dividido e até mesmo equilibrado entre duas unidades sociais básicas: o indivíduo (o sujeito das leis universais que modernizam a sociedade) e a pessoa (o sujeito das relações sociais, que conduz ao polo tradicional do sistema). Entre os dois, o coração dos brasileiros balança. E no meio do dois a malandragem, o "jeitinho" e o famoso e antipático "sabe com quem está falando?" seriam modos de enfrentar essas contradições e paradoxos de modo tipicamente brasileiro.

A máquina do jeitinho brasileiro apresenta sua nascente. É o que chamamos de corrupção em processo inicial. É no bairro, nas ruas, na fila do banco, na repartição pública, no uso fraudulento de carteirinhas para obtenção de meia entrada nos cinemas e teatros, que nasce a corrupção.

São as pequenas corrupções, na grande maioria das vezes realizadas sob a desculpa da insignificância, ou como forma de superar o "excesso de burocracia", que dão sustentação às grandes corrupções experimentadas no Brasil.

É a atitude de recém-desempregado que, ao conseguir um novo emprego, pede ao empregador para não ter seu contrato de trabalho registrado, de forma a continuar recebendo as parcelas do seguro-desemprego. São essas atitudes que moldam, desde muito cedo, o caráter dos brasileiros e lhe dão o tão famoso "jogo de cintura" que nada mais é que uma derivação do jeitinho brasileiro.

${ }^{29}$ DA MATTA, Roberto. O que faz o brasil, Brasil?. Rio de Janeiro: Rocco, 1986. p. 97. 
É o (a) beneficiário do bolsa-família que, mesmo podendo trabalhar, com carteira registrada, prefere a informalidade para não perder a benesse do governo. São os atestados médicos solicitados quando o funcionário se ausenta por qualquer motivo, ainda que não o de saúde. A corrupção não começa em um gabinete, mas na rua, no bairro, na escola, no sindicato, na política, nas relações diárias. Ela está no DNA de muitos brasileiros, sendo parte da cultura de nosso povo ${ }^{30}$.

\section{Jeitinho brasileiro e seus reflexos na morosidade da justiça}

Do ponto de vista da morosidade da justiça, o "jeitinho" brasileiro tem papel preponderante. Como ressaltado anteriormente, o excesso de formalismo e a criação excessiva de leis fazem com que muitas delas sejam desrespeitadas. Quando isso acontece, sendo vedada a autotutela, o Poder Judiciário é o destino certo daqueles que pretendem ver a lei cumprida, como também daqueles que não querem cumpri-la.

Apenas para se ficar na questão que mais aflige os brasileiros - a carga tributária - que é uma das maiores do mundo ${ }^{31}$, obriga aos contribuintes, sejam pessoas físicas ou jurídicas, além de suportar elevada carga, a cumprirem inúmeras obrigações acessórias, decorrentes de um sem-número de leis, decretos, portarias, regulamentos que tornam a observância das obrigações tributárias quase que impossível. Efeito prático disso é que temos, o Estado, com sua ânsia arrecadadora, como o maior cliente do Poder Judiciário e o principal causador da morosidade, mormente porque está sempre em um dos polos da relação.

\footnotetext{
${ }^{30}$ NETO, Pedro Rodrigues. A culpa é do jeitinho brasileiro. São Paulo: Novos Talentos, 2014. p. 18.

${ }^{31}$ De acordo com o estudo divulgado anualmente pelo Instituto Brasileiro de Planejamento e Tributação - IBPT, o brasileiro, nesse ano trabalhará 153 dias, ou cinco meses e um dia somente para pagar tributos, ou seja, para engordar os cofres públicos, levando em conta que 2016 é um ano bissexto, ou seja, com 366 dias no seu total. Os cidadãos brasileiros tiveram ainda que destinar em média 41,80\% do seu rendimento bruto em 2016 para pagar a tributação sobre os rendimentos, consumo, patrimônio e outros. Nos anos de 2014 e 2015 o índice permaneceu o mesmo: de 41,37\%. O estudo "Dias Trabalhados para pagar Tributos", criado pelo IBPT, considera a tributação incidente sobre rendimentos, formada pelo Imposto de Renda Pessoa Física, contribuições previdenciárias e sindicais; e a tributação sobre o consumo de produtos e serviços, como PIS, COFINS, ICMS, IPI, ISS etc.; e a tributação sobre o patrimônio, onde se incluem IPTU, IPVA. As taxas de limpeza pública, coleta de lixo, emissão de documentos e contribuições, como no caso da iluminação pública também são consideradas. INSTITUTO BRASILEIRO DE PLANEJAMENTO E TRIBUTAÇÃO. Brasileiro trabalha até 1 de junho só para pagar impostos. 2016. Disponível em: <https://www.ibpt.com.br/noticia/2465/Brasileirotrabalha-ate-1o-de-junho-sopara-pagar-impostos>. Acesso em: 10 ago. 2016
} 
Nesse contexto, "o jeitinho" brasileiro e sua irmã gêmea, a corrupção, surgem como uma solução, uma alternativa, um "jeitinho", para se evitar o cumprimento das obrigações legais, que, a despeito de serem justas ou não, estão inseridas em nosso ordenamento jurídico e devem ser observadas.

Surgem, assim, consultorias especializadas em planejamento tributário (em alguns casos com nítidos contornos de evasão fiscal e não elisão fiscal ${ }^{32}$ ) escritórios de advocacia com suas teses objetivando reduzir ou diferir o pagamento de tributos, a indústria das liminares, os despachantes de todas as ordens (aduaneiros, veiculares, consulares) os fiscais que, ao invés de orientarem, criam "dificuldades para vender facilidades".

Voltando nossos olhares para a rotina diária das repartições públicas, em especial a forense, constatamos que há varas judiciais nas quais, alguns processos, independentemente da complexidade da matéria objeto de julgamento, possuem um trâmite mais ágil do que os demais.

Nesses casos, verifica-se que os laços afetivos, decorrentes da pessoalidade, da afinidade ou mesmo da troca de favores, entre advogados, partes e serventuários da justiça, fazem com que rotinas administrativas, que fazem parte do rol de obrigações do funcionário, sejam feitas com maior ou menor grau de celeridade, zelo e prestatividade. É o jeitinho brasileiro resolvendo, individualmente, um problema que é de toda a coletividade, qual seja, a demora na prestação jurisdicional.

\section{CONCLUSÃO}

Durante o presente trabalho buscou-se verificar em que medida as pequenas corrupções diárias, a flexibilidade ética e moral do brasileiro e que compõe o fenômeno denominado "jeitinho brasileiro", podem contribuir para o aumento da morosidade da justiça.

Sabendo-se que o problema da morosidade não é recente e tampouco privilégio da Justiça brasileira, verificamos que a crise do Poder Judiciário e a consequente ampliação da

\footnotetext{
${ }^{32}$ Elisão fiscal é a prática pela qual o contribuinte, antes da ocorrência do fato gerador da obrigação tributária, se vale de atos lícitos que resultam na menor onerosidade fiscal. Evasão fiscal é a prática, concomitante ou posterior à incidência do fato imponível, a qual se utiliza de formas defesas em lei (simulação, fraude ou sonegação) para se esquivar de pagar tributos.
} 
morosidade nele experimentada decorrem, em parte, do padrão cultural e evolutivo de nossa sociedade, aliado às novas demandas, fruto dos tempos contemporâneos e decorrentes de uma sociedade em que valores como "ter" são elevados à categoria de bem universal em detrimento do "ser", o que vai redundar no aumento das disputas e, consequentemente, do número de demandas.

Tendo em vista as dimensões do Brasil, podemos afiançar que somos um país continental, falamos uma única língua e possuímos valores e tradições que nos aproximam. Por esses motivos, a cultura brasileira é baseada na pessoalidade, na qual o interesse individual ou de um pequeno grupo se sobrepõe aos da coletividade, sendo esse o pano de fundo para a gestação de um produto genuinamente nacional, o chamado "jeitinho brasileiro, caracterizado pela busca por atalhos, pelo improviso e pela flexibilidade no cumprimento de suas obrigações.

Nesta toada, o "jeitinho brasileiro" se alastra em toda a sociedade, sem distinguir raça, religião, orientação política ou posição social. Não é exclusivamente um organismo de adaptação à realidade institucional brasileira, mas, também, um componente da identidade nacional e que possui feições positivas e negativas.

Temos, então, que as pequenas corrupções diárias realizadas sob o argumento da insignificância, ou como meio de se livrar do "excesso de burocracia", contribuem, demasiadamente, para o aumento da morosidade da justiça.

\section{REFERÊNCIAS}

ABREU, Gabrielle Cristina Machado. A duração razoável do processo como elemento constitutivo do acesso à justiça. Florianópolis: Conceito Editorial, 2008.

ARISTÓTELES. A política. Rio de Janeiro: Ed. De Ouro, v.I., 1965.

Ética a nicômaco. 6.ed. São Paulo: Martin Claret, 2001.

BARBOSA, Livia. O jeitinho brasileiro: a arte de ser mais igual do que os outros. Rio de Janeiro: Elsevier, 2006.

BARROS, Betania Tannure de; PRATES, Marco Aurélio. O estilo brasileiro de administrar. São Paulo: Editora Atlas, 1996. 
BAUMAN, Zygmunt. Globalização: as consequências humanas. Rio de Janeiro: Zahar, 1999.

Modernidade líquida. Rio de Janeiro: Jorge Zahar, 2001.

BERTASO, João Martins. A cidadania moderna: a leitura de uma transformação. In: DALLARI JÚNIOR, Arno; OLIVEIRA, Odete Maria de. (orgs.) et al. Cidadania e nacionalidade: efeitos e perspectivas: nacionais - regionais - globais. Ijuí: Unijuí, 2002.

BURNS, Barbara Helen. Teaching cross-cultural missions based on biblical theology. Implications of ephesians for the brazilian church. Deerfield, Illinois: Trinity. Tese (não publicada), 1987

DALLARI JÚNIOR, Arno; OLIVEIRA, Odete Maria de. (orgs.) et al. Cidadania e nacionalidade: efeitos e perspectivas: nacionais - regionais - globais. Ijuí: Unijuí, 2002.

BONAVIDES, Paulo. Do estado liberal ao estado social. 6.ed. São Paulo: Malheiros, 1996.

CARVAlHO, José Murilo de. Cidadania no Brasil: o longo caminho. 19.ed. Rio de Janeiro: Civilização Brasileira, 2015.

CHIAVENATO, Júlio José. Ética globalizada \& sociedade de consumo. 2.ed. São Paulo: Moderna, 2004.

DA MATTA, Roberto. O que faz o brasil, Brasil? Rio de Janeiro: Rocco, 1986.

ESTADO DE SÃO PAULO. Caderno Olimpíadas. Edição de 1 ago. 2016. Disponível em: <http://digital.estadao.com.br/home.asp>. Acesso em: 06 ago. 2016.

FALCÃO, Joaquim. Estratégias para a reforma do Poder Judiciário. In: RABELLO, Sérgio;

RENAUlT, Tamm; BOTTINI, Pierpaolo. (coord.) Reforma do Poder Judiciário. São Paulo: Saraiva, 2005.

FAORO, Raymundo. Os donos do poder. Porto Alegre: Globo, 2000.

FREYRE, Gilberto. Casa-grande \& senzala. 43.ed. Rio de Janeiro: Record, 2001.

HOFFMAN, Paulo. O direito à razoável duração do processo e a experiência italiana. In: WAMBIER, Teresa Arruda Alvim et al. Reforma do Poder Judiciário: primeiros ensaios críticos sobre a EC 45/2004. São Paulo: Revista do Tribunais, 2005. 
HOLANDA, Sérgio Buarque. Raízes do Brasil. 26.ed. São Paulo: Companhia das Letras, 1995.

INSTITUTO BRASILEIRO DE PLANEJAMENTO E TRIBUTAÇÃO. Brasileiro trabalha até 1 de junho só para pagar impostos. 2016. Disponível em: <https://www.ibpt.com.br/noticia/2465/Brasileiro-trabalha-ate-1o-de-junho-so-parapagarimpostos>. Acesso em: 10 ago. 2016.

KANT, Immanuel. Crítica da razão pura. 3.ed. São Paulo: Nova cultural, 1987.

MANCUSO, Rodolfo de Camargo. Acesso à justiça: condicionantes legítimas e ilegítimas. São Paulo: Revista dos Tribunais, 2011.

NALINI, José Renato. Ética geral e profissional. 10.ed. São Paulo: Editora Revista dos Tribunais, 2013.

. Há esperança de justiça eficiente?. In: SILVEIRA, Vladmir Oliveira da; MEZZAROBA, Orides (coord.). Justiça e [o paradigma da] eficiência. São Paulo: Revista dos Tribunais, v.1., 2011.

NETO, Pedro Rodrigues. A culpa é do jeitinho brasileiro. São Paulo: Novos Talentos, 2014. NICOLLIT, André Luiz. A duração razoável do processo. Rio de Janeiro: Lumen Juris, 2006.

OLIVEIRA TORRES, João Camilo de. Interpretação da realidade brasileira. Rio de Janeiro: José Olympio, 1973.

PORTAL JOGOS LIMPOS. Olimpíadas. Disponível em: $<$ http://www.jogoslimpos.org.br/destaques/olimpiada-rio-2016-deve-custar-r-367-bilhoes/>. Acesso em: 06 ago. 2016.

REGA, Lourenço Stelio. Dando um “jeitinho" no jeitinho: como ser ético sem deixar de ser brasileiro. São Paulo: Mundo Cristão, 2000.

RIBEIRO, Darcy. O povo brasileiro: a formação e o sentido do Brasil. 2.ed. São Paulo: Companhia das Letras, 1995.

RIGGS, Fred Warren. A ecologia da administração pública. Rio de Janeiro: FGV, 1966. 
SARLET, Ingo Wolfgang. Dignidade da pessoa humana e direitos fundamentais na Constituição Federal de 1988. 5.ed. Porto Alegre: Livraria do Advogado, 2007.

SILVEIRA, Vladmir Oliveira da; ROCASOLANO, Maria Mendez. Direitos humanos: conceitos, significados e funções. São Paulo: Saraiva, 2010.

STRECK, Lenio Luiz; MORAIS, José Luis Bolzan de. Ciência política e teoria do estado. 7.ed. Porto Alegre: Livraria do Advogado, 2012.

VÁZQUEZ, Adolfo Sanchez. Ética. 28.ed. Rio de Janeiro: Civilização Brasileira: 2006.

VIEIRA, Liszt. Cidadania e globalização. 4.ed. Rio de Janeiro: Record, 2000. 